\title{
O OLHAR HUMANIZADOR DE CLARICE LISPECTOR ANTE A ARBITRARIEDADE DO DIREITO DE PUNIR
}

\section{Adriana Yokoyama ${ }^{1}$}

Resumo: O trabalho objetiva abordar a relação política e resistente da obra de Clarice Lispector em duas de suas narrativas: Observações sobre o direito de punir (2005), e Mineirinho (1999). Objetivando uma reforma no sistema penitenciário brasileiro, Clarice escreve sobre a necessidade de um dever de punir no intuito de restituir à vida a sua normalidade. Em Mineirinho, a escritora, imersa em um sentimento de compaixão, sente a morte de um bandido assassinado com treze tiros pela polícia carioca, trazendo em si os questionamentos em relação às formas de penalização legitimadas pelo Estado. Este trabalho cerca-se da apreensão de obras cuja significação nos auxilia na compreensão da condição humana, dando-nos suporte para o aprofundamento não apenas de nossas próprias reflexões, mas também do outro. As narrativas analisadas projetam-se no recorte de um contexto social que, embora distanciados por duas décadas, aproximam-se pela mesma percepção: o sentimento de revolta ante as manifestações autoritárias do Estado, aliadas a um dever de justiça e de uma política de recuperação a partir das bases. Essa discussão ganha considerável proporção à medida que aborda os estudos memorialísticos e identitários, identificando, sob a face da mesma autora, o viés social, político e autoritário do Estado. Essas narrativas, que se propõem a um processo de intertextualidade, evocam associações que demonstram a importância dessas relações para analisar e esclarecer os diferentes olhares e os aspectos interrelacionais presentes na obra.

Palavras-chave: Clarice Lispector. Memória. Autoritarismo.

\begin{abstract}
The paper aims to address the political and resistant relationship of Clarice Lispector 's work in two of his narratives: Observations on the right to punish (2005), and Mineirinho (1999). Aiming for a reform in the Brazilian penitentiary system, Clarice writes about the need for a duty to punish in order to restore life to its normality. In Mineirinho, the writer, immersed in a feeling of compassion, feels the death of a bandit assassinated with thirteen shots by the police of Rio de Janeiro, bringing in itself questions regarding the forms of penalization legitimized by the State. This work surrounds the apprehension of works whose meaning helps us in understanding the human condition, giving us support for the deepening not only of our own reflections, but also of the other. The narratives analyzed are projected in the excerpt from a context of a social, which although distanced by two decades, are approached by the same perception: the feeling of revolt before the authoritarian manifestations of the State, coupled with a duty of justice and a policy of recovery from the bases. This discussion gains a considerable proportion as it approaches the memorialistic and identity studies, identifying, under the face of the same author, the political and authoritarian bias of the state. These narratives, which propose a process of intertextuality,
\end{abstract}

\footnotetext{
${ }^{1}$ Doutoranda (Bolsista Capes) em Estudos Literários do Programa de Pós-Graduação em Letras da Universidade Federal de Santa Maria (UFSM), orientada pela Prof. ${ }^{a}$ Dr. ${ }^{a}$ Rosani Ketzer Umbach e participante do grupo de pesquisa "Literatura e Autoritarismo". E-mail:adrianayokoyamaa@gmail.com
} 
evoke associations that demonstrate the importance of these relations to analyze and clarify the different perspectives and the interrelational aspects present in the work.

Keywords: Clarice Lispector. Memory. Authoritarianism.

\section{Introdução}

Este trabalho é fruto da constatação de que a força do discurso literário de Clarice Lispector é capaz de aludir à criação de novos horizontes de compreensão e reconhecimento da condição humana. O efeito perturbador de sua escrita, que ultrapassa a enunciação e possibilita ao leitor uma sondagem das experiências vividas, seja ela sua ou do outro ${ }^{2}$, para a intelecção de sua existência, pode ser percebido por intermédio das sucessivas reedições que conferem à sua obra, não apenas o enorme interesse nos estudos e pesquisas críticas em diferentes vertentes (filosóficas, psicológicas, políticas, sociológicas...) como também a atualidade de uma das maiores escritoras da literatura brasileira contemporânea. Nesse sentido, o presente trabalho pretende abordar a relação de identidade, memória e autoritarismo na obra de Clarice Lispector, tendo como corpus literário duas narrativas: Observações sobre o direito de punir (ensaio), publicada na revista $A$ Época em 1941, mais tarde reunida no livro Outros Escritos (2005), e Mineirinho (crônica) publicada na revista Senhor em 1962, constando, atualmente, no livro Para não esquecer (1999).

Os temas aqui propostos, questionamentos sobre o direto de punir e o assassinato brutal de um bandido chamado Mineirinho, embora distanciados por duas décadas, têm como intuito estabelecer uma analogia entre eles, por trazerem à tona assuntos do nosso cotidiano, ainda em atividade, e por apresentarem feridas não cicatrizadas, tanto na imposição de um autoritarismo social velado, como na construção da identidade através da memória individual e coletiva. O ensaio de 1941 é uma reflexão sobre a essência da punição, sobre o poder do Estado em manter a ordem social em defesa de sua legitimidade por meio da aplicação da lei. Porém, o que intrigou a escritora é que essa punição não era científica e impessoal, nela entrava muitos sentimentos individuais, entre eles o sadismo. Por isso defendia a

\footnotetext{
${ }^{2}$ A expressão o "Outro" tem sua significação, segundo Michael Pollak (1992), como um indivíduo capaz de possibilitar a construção de uma identidade.
} 
ideia de um dever de punir, no sentido de restituir a vida à sua normalidade. (LISPECTOR, 2005, p. 48). Na crônica, Mineirinho, Clarice entrega-se ao total aprofundamento do ser ao receber a notícia da execução desse bandido, com treze tiros, e faz uma autoavaliação na tentativa de tentar entender essa atrocidade e o seu lugar no mundo.

Nesse contexto, pretendemos mergulhar na escrita de Clarice Lispector e evidenciar, no âmbito de uma realidade que perpassa o simples relato, toda a trajetória de uma inquietação passada, que se reflete no presente, por meio da alteridade, sem deixar de conduzir-se ao direcionamento autoritário do Estado. Nosso intuito é comprovar que, no uso de sua memória individual, a escritora, ao receber a notícia do assassinato de mineirinho, retoma a memória na literatura (UMBACH, 2008, p. 12) em seu texto de 1941 e tenta, por intermédio da subjetividade e sua visão no outro, compreender o papel social do indivíduo na (re)construção de uma identidade, analisadas também sob o autoritarismo do Estado em conceder ou não aos excluídos a oportunidade de escolha, focando na história de Mineirinho. E, principalmente, identificar como essa memória individual de Clarice auxilia no processo da construção de identidades coletivas.

As narrativas, unidas, ganham espaço em nossas pesquisas pela formação de uma linguagem que possibilita o encontro de estudos memorialísticos no processo de apreensão e construção da identidade. Tais narrativas, nesse contexto, deslocam-se do lugar-comum para atingir uma visão pouco explorada em relação às vertentes já debatidas em Clarice Lispector. É a visão social e política da escritora, ante ao assassinato de Mineirinho, que nos conduz ao aprofundamento das relações que envolvem o Estado e sua legitimidade.

\section{Análise das narrativas de Clarice Lispector: Observações sobre o direito de punir e Mineirinho}

O ensaio de 1941, Observações sobre o direito de punir, apresenta-se como uma proposta de inserir, no contexto jurídico, uma lei que possa modificar o sistema penal brasileiro. Seu ingresso na Faculdade Nacional de Direito da Universidade do Brasil, em 1939, deve-se a influência de seu pai que observou em Clarice uma 
atitude de luta e reivindicação pelos direitos humanos, acreditando ser a advocacia uma profissão a contento de suas atitudes. O comentário de seu amigo jurista e professor, Tiago Dantas, de que a escolha do Direto Penal no âmbito da advocacia, não designa um advogado, e sim um literato, provavelmente colaborou para que a escritora compreendesse sua verdadeira vocação. Pois, embora concluindo seu curso, a escritora nunca voltou para buscar seu diploma. Foi ainda durante o curso, que Clarice escreve a narrativa em questão (LISPECTOR, 2005, p. 43).

Pretendendo uma reforma no sistema penitenciário do país, a narrativa reflete sobre a expressão, direito de punir, no intuito de comprovar a arbitrariedade desse termo. Para ela, existe apenas um poder de punir que se coloca à disposição do Estado para a execução, no sentido lato ${ }^{3}$ da palavra, de tais ações. A escritora, em toda sua perspicácia, apresenta argumentos que se dissociam do termo por entender a instabilidade e a relatividade da mente humana em relação ao conceito de punição, principalmente, em relação aos critérios de julgamento e qualificação de um ato como sendo criminoso ou não. Essa questão, que se desloca para o contexto histórico das instituições, ao sentirem-se ameaçadas pela tentativa de um entrecruzamento de atos e decisões que não comungam com as vigentes, encontra no termo punição um ato de defesa. É a maneira encontrada pelas instituições para que um novo poder paralelo não se estabeleça em seus domínios.

Essa percepção da instauração de um direito/poder sobre a sociedade tem no ensaio de Clarice, a hipótese de sua origem e de seu desenvolvimento. Segundo a autora, "desde que o homem pôde vingar a ofensa a ele dirigida, e verificou que tal vingança o satisfazia e atemorizava a reincidência, só deixou de exercer sua força perante uma força maior" (LISPECTOR, 2005, p. 46). Foi a partir dos excessos desses atos de vingança, que os mais fracos uniram-se, compondo uma sociedade distinta. Dessa união, imbuída pela racionalidade, foram instituídas novas noções de caridade, justiça, igualdade, criando-se uma espécie de superego capaz de reger e fiscalizar o relacionamento do ser humano com a nova sociedade que se formava, impedindo a inserção de atos considerados proibidos. Essa noção foi aos poucos extinguindo o uso da força bruta nas relações humanas, dando lugar ao estabelecimento de leis que puniam os atos que fossem contra as leis vigentes.

\footnotetext{
${ }^{3}$ Compreendemos a palavra execução em seu sentido mais amplo: execução de leis atrelada à execução de atitudes que dizem respeito à necessidade de punição sejam elas aceitáveis ou não.
} 
Contudo, são os indivíduos mais capazes que estão habilitados a vigiar e observar as leis, mantendo a estabilidade social, ou seja, o Estado em sua primeira formação ideológica. É o estabelecimento da vigência do poder, do "direito de punir" estabelecido pelo apoio de todos os indivíduos que precisam das leis para sobreviver.

Podemos correlacionar essa forma de defesa das instituições, com uma das concepções mais pertinentes em relação a esse tipo de poder, advindas das reflexões do sociólogo Max Weber (1956) que nos apresenta Os três tipos puros de dominação legítima (dominação carismática, tradicional e legal), esclarecendo e auxiliando nossa pesquisa no entendimento da força desse poder como uma forma de

dominação legal em virtude de estatuto. Seu tipo mais puro é a dominação burocrática. Sua idéia básica é: qualquer direito pode ser criado e modificado mediante um estatuto sancionado corretamente quanto à forma. [...] Obedece-se não à pessoa em virtude de seu direito próprio, mas à regra estatuída, que estabelece ao mesmo tempo a quem e em que medida se deve obedecer. [...] O tipo daquele que ordena é o "superior", cujo direito de mando está legitimado por uma regra estatuída, no âmbito de uma competência concreta [...] (WEBER, 1956 p. 1-2).

Ou seja, na dominação legal, o Estado detém o poder porque ocorre a partir de uma legislação; de um trâmite legal, e sua punição está baseada em leis específicas, pois punir é sua forma de manter o monopólio da força. É sobre esse direito que a escritora contesta, pois "a sociedade, porém, mais sabiamente, prefere falar num 'direito de punir' força unilateral, garantidora de uma boa defesa contra o ataque à sua estabilidade" (LISPECTOR, 2005, p. 43). Essa constatação reforça sua hipótese na existência, não de um direito, mas de um poder de punir que até hoje traz em suas raízes os resquícios de um passado punitivo pelo sabor da vingança.

O que nos move nesta crônica é a sensibilidade de Clarice em nos conceder, ainda que instantaneamente, devido a suas poucas linhas, a oportunidade de percebermos o quão entrelaçadas estão as ideias legislativas aos sentimentos pessoais e contraditórios, expressando, muitas vezes, atitudes sádicas na execução das leis. Portanto é a respeito desse aspecto que Clarice revê uma utilização dual desse termo por entender a existência desse direito como de defesa, de 
impedimento e de luta. É pela responsabilidade de direcionar e restituir a vida àqueles que subverteram algumas regras, e em atitudes de defesa a sociedade e ao combate a reincidência de um crime, que Clarice reforça a ideia de reforma no sistema penal, pois para ela o que cabe nessa significação é o dever de punir, isso é o essencial: procurar sanar os males da sociedade.

Em sua outra produção, o assassinato de um homem chamado José Miranda Rosa, mais conhecido como Mineirinho, que foi transformado em título da crônica escrita em 1962, por Clarice Lispector, narra a história de um dos bandidos mais procurados pela polícia carioca nesse período. Considerado uma espécie de Robin Hood da favela, Mineirinho foi assassinado pela polícia no dia 10 de maio de 1962 , veiculando, com sua morte, uma grande extensão de notícias jornalísticas. Embora contraventor, Mineirinho, era admirado e respeitado por seus amigos e vizinhos na comunidade em que morava: na favela da Mangueira, no Rio de Janeiro. Pois à maneira do anti-herói inglês, Mineirinho roubava dos ricos para dar aos pobres. A repercussão de suas ações deu-se devido as suas inúmeras investidas, à luz do dia, a lojas e comércio da cidade, inclusive promovendo atentados contra a Polícia Militar do Rio de Janeiro, causando verdadeiro transtorna a sociedade. Foi preso por três vezes, fugindo de todas elas e prometendo se vingar. Por suas atitudes subversivas e fora- da- lei, a prisão de Mineirinho passou a ser uma questão de honra para restituir a paz e a tranquilidade da cidade. Capturado, Mineirinho foi brutalmente assassinado, pela polícia, com treze tiros à queima roupa, noticiando todos os veículos de comunicação da época.

Nessa narrativa, Clarice entrega-se ao total aprofundamento do ser ao receber a notícia da execução desse bandido com treze tiros, e faz uma autoavaliação na tentativa de tentar entender essa atrocidade e o seu lugar no mundo. Publicada pela primeira vez, na revista Senhor, com o título Um grama de radium-Mineirinho, a crônica descreve minuciosamente o sentimento de impotência mediante a supremacia e ao estabelecimento do poder. Inundada por sensações contraditórias, a escritora sente a dor da morte de Mineirinho, em plena consciência da legitimidade do Estado em executar a punição. É sobre essa punição, esse dever de punir, baseado em atitudes primitivas, que a escritora revoga.

$\mathrm{O}$ impacto do assassinato de Mineirinho, em Clarice, insere-a em um contexto social muito mais amplo, pois a excentricidade do fato aliada à sensibilidade de uma 
escritora que faz da literatura o seu veículo de compreensão de si e do mundo, recria, sob as bases da crueldade, um sentimento de humanização e conscientização. É a forma que ela encontra de utilizar a palavra como mediadora de um discurso que carrega em si a própria realidade e a verdade das coisas. Segundo sua descrição, o que a atormentava ainda mais neste fato era a maneira como Mineirinho foi assassinado: com treze tiros. Embora o relato refira-se a um infrator, um facínora, como mencionado algumas vezes por Clarice Lispector, em sua crônica, trata-se de um ser humano. Esse seu olhar aguçado no outro, uma característica de sua escrita literária, é percebido diretamente em seu relato após questionar sua cozinheira sobre o caso de Mineirinho: "Vi no seu rosto a pequena convulsão de um conflito, um mal- estar de não se entender o que se sente, o de precisar trair sensações contraditórias por não saber como harmonizá-las" (LISPECTOR, 1999, p. 123). É interessante observarmos que essas sensações contraditórias que mesclam sentimentos de defesa, responsabilidade e humanidade atuam no interior da própria narradora, pois é Clarice que em sua subjetividade escreve para tentar organizar suas próprias ideias.

O fato de a escritora referir-se a um contraventor reside na brutalidade das ações, que são reflexos da não compreensão de uma política penal que entenda esse direito de punir, como um "dever de punir", conforme mencionado na crônica anterior. É inegável a intrínseca relação entre as crônicas de 1941 e 1962, pela interpenetração de uma consciência e uma ideologia que a partir da produção literária alcança o âmbito das relações jurídicas, sociais e antropológicas. Se levarmos em conta os conceitos primários de organização social perceberemos que desde o início, no principio de todas as coisas- das leis Divinas-somos colocados à disposição de regras que nos fornecem as diretrizes para uma boa convivência. E é por acreditar nessas determinações, que a escritora remonta em sua obra esses conceitos primários na tentativa de compreender o que parece escapar aos olhos dos poderes dominantes. Para ela, a lei que determina: não matarás, a lei que protege corpo e vida, é a sua garantia de vida, bem como de resguardo pelo reconhecimento de uma lei de proteção para ambas as partes. Essa defesa que se estende as camadas jurídicas, por dupla obrigação, deveria ser cumprida, porém, no caso de Mineirinho, é visível o rompimento dessa regra. 
Munida de um sentimento paradoxal, a escritora, ancorada no suporte e na legitimidade do Estado em defender seus cidadãos, reage em legítima defesa ante a caracterização de uma ação brutal por parte daqueles que nos deveriam prestar socorro. São os treze tiros que mataram Mineirinho que desencadeiam uma infinidade de reflexões contraditórias, de dores e desilusões pela instituição de um poder autoritário que, no exercício de seu "direito de punir" não se baseiam em uma "pena científica, impessoal, mas [...] dos sentimentos individuais dos aplicadores do direito (como sejam o sadismo e ideia de força que confere o poder de punir" (LISPECTOR, 2005, p. 48), de acordo com a percepção de Clarice em sua narrativa de 1941.

A sensação de pequenez e de impotência, e mais ainda, a dificuldade de alcance e completude mediante os fatos, é que faz Clarice Lispector descrever tão intensamente os treze tiros que mataram Mineirinho:

\begin{abstract}
Esta é a lei. Mas há alguma coisa que, se me faz ouvir o primeiro e o segundo tiro com alívio de segurança, no terceiro me deixa alerta, no quarto desassossegada, o quinto e sexto me cobrem de vergonha, o sétimo e o oitavo eu ouço com o coração batendo de horror, no nono e no décimo minha boca está trêmula, no décimo primeiro digo em espanto o nome de Deus, no décimo segundo chamo meu irmão. $O$ décimo terceiro tiro me assassina- porque eu sou o outro. Porque eu quero ser o outro (LISPECTOR, 1999, p. 124).
\end{abstract}

A instituição que pune Mineirinho ainda é a mesma que se apóia nos resquícios de uma decisão calcada na vingança a uma ofensa, ao ataque a instituição vigente e a proliferação violenta de resultados que fogem a normalidade, mas baseada na brutalidade. É o poder de punir que assusta a escritora, pois a justiça que vela o seu sono é a mesma que a acorda e a perturba com os treze tiros dirigidos a Mineirinho. A composição de sua narrativa cerca-se da percepção e da decepção de uma conformidade mediante o regime instituído. De acordo com Clarice, os sonsos essenciais somos todos nós que, diante da necessidade de segurança, abandonamos a nossa força, revolta e amor, cedendo lugar ao esquecimento e ao conformismo. Portanto, é a partir dessa nossa falsa salvação que podemos reconhecer que a constituição da persona de Mineirinho é em si o nosso próprio erro. Conforme sua percepção, o erro de perceber o que em silêncio fizemos de um homem (LISPECTOR, 1999, p. 124). 
Em Mineirinho, Clarice reconhece a importância de se encontrar preciosidade no erro, pois somente a partir desse encontro é que poderemos enfim no salvar. Essa salvação de que fala Clarice, parte do princípio do reconhecimento de que existe algo a fazer, de que vidas podem ser modificadas mediante a percepção de um olhar direcionado ao outro. Contudo, a própria condição de Mineirinho é elemento essencial para a sua transformação. A violência, característica das atitudes deste facínora é, para Clarice, uma violência inocente, "não nas consequências, mas em si inocente como a de um filho de quem o pai não tomou conta" (LISPECTOR, 1999, p. 124). Esta passagem demonstra claramente o engajamento de Clarice ao defender a reforma no sistema penitenciário brasileiro, em Observações sobre o direito de punir (Tendo sua primeira publicação em 1941). Tal compreensão que se caracteriza na recuperação, no dever de punir, sob as bases de leis e diretrizes jurídicas que, imbuídas de uma responsabilidade social, possam tratar e direcionar esses indivíduos a um caminho mais digno, parte da concepção primordial de um amparo humanizador, desde suas bases, e socialmente mais acessível às camadas mais desfavorecidas da sociedade.

A defesa de Mineirinho deve-se ao fato de ser ele uma vítima desse poder punitivo e legítimo do Estado que, ao conduzir seus próprios métodos e utilizar inúmeras alternativas para consolidar sua força, excede-se em sua liberdade de ação. A tarefa (crônica) encomendada pela revista Senhor a Clarice Lispector, apresenta a descrição de um relato em que violência e o sentimento de compaixão encontram-se inteiramente conectados. A sensibilidade da escritora ante a percepção de uma infração de Mineirinho endossa as inúmeras críticas que revelam a qualidade essencialmente humanizadora de Clarice. $O$ fato de a escritora assumirse como esse outro que, dilacerado talvez inconformado, ao contrário de muitos de nós, diante de uma realidade cruel oferecida sem alternativa, possibilitou um dos entrosamentos mais significativos da obra, pois, em sua visão, o que se tornou punhal em Mineirinho, é o mesmo que a faz dar água a um homem, não que ela possua, mas porque ela sabe o que é sentir sede. (LISPECTOR, 1999, p. 125). Errante, Mineirinho viveu tentando acertar, ou pelo menos, na esperança de suprir, enredado pelas aventuras de Robin Hood, e sua coragem de destruição, as lacunas deixadas por um Estado que a cada dia mais se mostra incapaz de levar pelas mãos aqueles que os apoiam. 
O estranhamento causado pelas inúmeras sensações contraditórias, na crônica de Clarice, traz á tona o desejo de uma justiça prévia. De uma justiça que possa compreender a verdadeira essência desse direito de punir e da palavra justiça. "Sobretudo uma justiça que olhasse a si própria, e que visse que nós todos, [...] somos escuros, e por isso nem mesmo a maldade de um homem pode ser entregue a maldade de outro homem: para que este não possa cometer livre [...] um crime de fuzilamento" (LISPECTOR, 1999, p. 126-127). O exagero dos treze tiros que assassinou Mineirinho foi e sempre será a prova de que o Estado, no auge de sua legitimidade, excedeu o seu poder livremente, pois, para a defesa de uma possível derrocada de sua instituição, a utilização da força bruta foi a sua resposta. Em entrevista a Júlio Lerner, em 1977, Clarice destaca essa produção como uma das mais importantes, talvez pela dureza dos fatos e a forma como foi atingida, como sentiu a revolta. Segundo Clarice "[...] qualquer que tivesse sido o crime dele, uma bala bastava. O resto era vontade de matar. Era prepotência" (LERNER, 1977).

\section{Considerações finais}

Abarcando conceitos sociais, políticos, memorialísticos e identitários, as crônicas Observações sobre o direito de punir e Mineirinho, refletem a preocupação de Clarice ante a supremacia do poder exercido pelo Estado e seus inúmeros excessos em relação ao grau de punição de seus indivíduos. Essa análise que se constitui em seu fator essencialmente identitário cerca-se de um imenso sentimento de humanização, por parte da escritora, na formação social, intelectual e essencialmente humana de indivíduos, como Mineirinho, que vivem às margens de uma sociedade que se pré-dispõe a defesa de seus colaborados, mas na realidade, propagam ainda a falta de discernimento em suas ações.

Aproximando essa relação de poder e legitimidade do Estado à contemporaneidade, no que concerne a constante ameaça do estabelecimento de uma nova instituição, a implementação da Unidade de polícia pacificadora (UPP), no Estado do Rio de Janeiro, desde 2008, que tem como principal objetivo a retomada do controle de comunidades dominadas pelo tráfico, é um grande exemplo do exercício dessa força unilateral que se compreende como um poder legitimado pelo Estado para combater o crime. Em sua política de proximidade do Estado com a 
população, a força que combate é a mesma que também dilacera. Pois, intimidar não significa modificar e nem mesmo reconstruir realidades, ao contrário, significa reproduzir a sensação de medo. Pois, segundo Clarice é necessário uma "justiça prévia que se lembrasse de que nossa grande luta é a do medo, e que um homem que mata muito é porque teve muito medo" (LISPECTOR, 1999, p. 126). E Mineirinho sentiu medo. Sendo assim, reproduzi-la é estar a todo o momento aguardando sua resposta. Muito mais do que uma política de aproximação, é necessário uma política de recuperação.

Dessa forma, podemos perceber que desde o ensaioB de 1941 até nossos dias, os reflexos da prepotência e da falta de compreensão ainda permanecem presentes. Somos nós os sonsos essenciais que diante do conformismo apoiamos uma justiça que se vinga, que não se permite a uma contestação.

\section{REFERÊNCIAS}

LISPECTOR, Clarice. Outros Escritos. Organização de Teresa Montero e Lícia Manzo. Rio de Janeiro: Rocco, 2005, p. 43-49.

. Para não esquecer. São Paulo: Rocco, 1999, p. 123-127.

LERNER, Júlio. Entrevista de Clarice Lispector. Disponível em:<http://www.youtube.com/watch?v=dji gdxUrPl>. Acesso em 5 de fevereiro de 2016.

POLLAK, Michael. Memória e identidade social. Estudos Históricos, Rio de Janeiro, vol. 5, n. 10, 1992, p. 200-212. Disponível em: http://bibliotecadigital.fgv.br/ojs/index.php/reh/article/view/1941/1080 Acesso em: 20 de outubro de 2014.

UMBACH, Rosani Úrsula ketzer. (Organizadora) Memórias da repressão. Santa Maria: UFSM-PPGL- editores, 2008, p.13-22.

WEBER, Max. Os três tipos puros de dominação legítima. 4a. ed.,organizada e revisada por Johannes Winkelmann. Tübingen,. J. C. B. Mohr (Paul Siebeck), 1956. v. II, p. 551-8. Trad. por Gabriel Cohn. Disponível em: http://www.mirelaberger.com.br/mirela/download/weber 3 tipos de dominacao.pdf Acesso em: 28 de outubro de 2014. 